\title{
Empirical Analysis on Bank's Net Interest Margin under the Background of Interest Rate Liberation: Taking the Banking Sector in Weihai for Example \\ Xiaoming Wang
}

Department of International Economics and Trade, Business School, Shandong University at Weihai, Weihai, 264209, China.

806339447@qq.com

\begin{abstract}
With the continuous reform of China's interest rate market, the deposit and lending spreads gradually narrowed, which undoubtedly makes the deposit and loan spreads as the main source of income of commercial banks face enormous challenges. For small and medium commercial banks, the situation is more severe. Taking the Banking Sector in Weihai for Example, by stata using quarter panel data from 2009 to 2012, Cross-sectional study differences of all kinds of bank's net interest margin, To determine the basis of its policies impact ability; Longitudinal study of 2012 in the middle of two microscopic effect of reform measures, and Combined with the macroeconomic factors, the optimal timing of implementation of policy Suggestions are put forwards.
\end{abstract}

Keywords: Interest rateliberalization; Net interest margin; Central bank benchmark spread.

\section{利率市场化背景下对银行净利差的实证分析

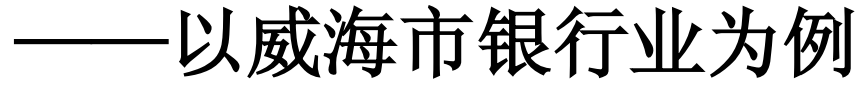

王晓明

(山东大学 (威海) 商学院、国际经济与贸易系, 山东省 威海市 264209)

摘要: 随着我国利率市场化改革的不断进行, 存贷利差呈现逐步收窄的趋势, 这无疑使以存贷利差为主要收入来源的商业 银行面临巨大的挑战。对中小型商业银行而言, 形势更是严峻。以威海市银行业为例, 通过 stata 利用 2009 年至 2012 年的季 度面板数据, 横向研究各类银行净利差的差异情况, 以判断其应对政策冲击的基础能力; 纵向研究 2012 年年中两次改革措 施的微观效果, 并结合宏观经济因素, 对政策的最佳实施时机提出建议。

关键词: 利率市场化; 净利差; 央行基准利差

引言

利率市场化改革的目的在于充分发挥利率机制在资源配置中的作用，并使之成为宏观调控的目标。从 目前的改革进程来看，境内的外币存款市场、货币市场和债券市场等都已经实现了利率的市场化，只是对 存款上限和贷款下限基准利率存在管制。而在改革的过程中，政策的效果和影响如何，是改革者尤为关心 的问题。

本文立足于利率市场化改革的最新进程，以山东省威海市的银行业为研究样本，利用 2009 年至 2012 年的季度面板数据, 横向研究各类银行净利差的差异情况, 以判断其应对政策冲击的基础能力; 纵向研究 2012 年年中两次改革措施的微观效果，并结合宏观经济因素，对政策的最佳实施时机提出建议。 


\section{1 文献综述}

\section{1 利率市场化理论简述}

总体上讲，支持利率市场化改革的西方经济学理论主要有凯恩斯的需求管理理论，以及罗纳德・麦金 农和爱德华 - 肖的金融深化理论, 而马克思关于利息和利率的理论也同样认为利率是在竞争的市场中形成 的。凯恩斯认为, 利率可以作为宏观经济政策调节的重要工具, 而以利率为核心的货币政策传导机制, 必 须依赖于利率形成过程的市场化。

\section{2 对国外改革的研究: 改革后实际利率与净利差的变化}

目前, 对外国的利率市场化改革的实践研究已经有相当多的成果。 20 世纪 80 年代起世界范围内出现 了利率市场化改革的热潮, 但改革过程不是一蹴而就的, 美国历时 16 年、日本历时 17 年完成了利率市场 化改革, 而韩国历经 30 年、前后三次进行利率市场化改革, 最终获得成功。利率市场化过程之所以困难 重重, 其主要原因在于利率放开后, 短期内会造成实际利率的上升。利率市场化对银行的盈利性具有十分 重要的影响, 这主要是通过净利差的变化来反映。

\section{3 国内研究: 存贷款利差变化与银行盈利状况的关系}

当前，我国学者对利率市场化的研究集中在对利率风险的管控和我国银行业的战略转型上，对利率市 场化改革中银行业的盈利性研究正处于起步阶段。黄金老（2001）将利率市场化产生的风险划分为阶段性 风险和恒久性风险, 指出利率市场化改革会使银行受到利率水平的骤然升高和不规则波动影响, 其脆弱性 更加显著, 甚至会导致银行危机的发生。王珏帅（2012）运用配对 $\mathrm{t}$ 检验的方法对商业银行在利差变化前 后的主要盈利指标进行比较, 发现当宏观经济处于繁荣阶段和在市场资金利率上升的情况下, 官方基准利 差的小幅收窄对银行盈利状况不会产生负面影响, 反之, 则会产生不利影响。 ${ }^{[4]}$ 央行出台的利率政策对国 有商业银行的盈利能力有很大影响, 高超（2012）对二者之间的关系进行了相关性分析，结果表明存贷利 率差和国有商业银行的盈利能力高度正相关，存款利率和国有商业银行盈利能力高度负相关。 ${ }^{[5}$

\section{4 对政策效果的观察与测量}

我国学者对于我国利率市场化改革的研究已经涉及到多个方面，在较为具体的改革路线上，制定了: “先外币，后本币; 先贷款，后存款；先农村，后城市; 先提高幅度，后方开” 的原则性方案; 在对银行 的影响研究上, 也从利差收窄等方面做了详细的分析。然而, 利率市场化对银行业的影响并不仅仅是停留 在利差缩小、银行业竞争加剧等直观层面。利率市场化改革会使金融风险的传播链条延续地广泛而深远, 因而对系统风险的防范成为利率市场化改革过程中必须给予足够重视的环节。

2 研究设计 本文主要通过建立计量经济学模型的实证方法, 来研究利率市场化改革政策对银行盈利性的影响。

\section{1 基本思路}

针对文章第一部分提到的 2012 年的这两次改革, 通过设置政策虚拟变量研究其政策效果有着客观的可行 性。

\section{2 样本选取及数据来源}

本文根据威海市 2009 年至 2012 年的银行业季度数据进行分析。本次实证研究的银行数据主要来源于 中国人民银行威海市中心支行、中国银行业监督管理委员会威海监督分局以及对威海市各银行的调研。鉴 
于从 2009 年起, 我国的宏观经济从金融危机的低谷逐渐恢复并趋于稳定，这使得本次实证分析较少地受 到宏观经济周期波动的影响；并且在这段期间内，威海市的银行种类趋于丰富，因此，本文采用 2009 年 至 2012 年四大类银行的季度面板数据进行分析，其他范围的数据不再考虑。

\section{3 模型指标的选取与计量模型的构建}

衡量银行存贷款利差的指标有多种，其中最常用的是净利差 ${ }^{1}$ （NIM，Net Interest Margin），本文 同样采用这一指标。

模型的具体形式为:

$$
N I M_{i t}=\alpha_{i}+\beta_{1} \operatorname{sav}_{i t}+\beta_{2} l_{e n}+\beta_{3} \operatorname{siz}_{i t}+\beta_{4} d 1+\beta_{5} d 2+u_{i}+\varepsilon_{i t}
$$

其中， $\varepsilon$ 为随机扰动项; $i=1,2,3,4,1$ 代表中资全国性大型银行， 2 代表中资全国性中小型银行， 3 代表 农村合作机构, 4 代表村镇银行; 当 $i=1,2,3$ 时, $t=1,2, \cdots \cdot 16$; 由于村镇银行从 2010 年第三季度开始 经营, 因此, 当 $i=4$ 时, $t=7,8, \cdots \cdots, 16$ 。

\section{3 模型的估计与分析}

\section{1 模型的估计与系数的涵义}

本文首先利用固定效应模型和随机效应模型对面板数据进行估计，并对两个模型的分析结果进行豪斯 曼检验，检验的最终结果支持固定效应模型。其次，本文也采用了 LSDV（最小二乘虚拟变量）方法对面板 数据进行估计, 其中的个体差异项都通过了显著性检验, 而这里的个体差异项就是判断四类银行净利差差 异的重要指标 ${ }^{2}$ 。综上所述, 对模型的估计采用固定效应模型和 LSDV 方法 ${ }^{3}$, 根据 STATA 分析结果进行整 理后的数据见表 4 。

表 4: 银行净利差决定模型的估计结果

\begin{tabular}{|c|c|c|c|c|}
\hline \multirow{2}{*}{ 变量名称 } & \multicolumn{2}{|c|}{ 固定效应（组内估计量） } & \multicolumn{2}{|c|}{ LSDV（最小二乘虚拟变量）估计 } \\
\hline & 系数估计值 & $\mathrm{P}$ 值（T 检验） & 系数估计值 & $\mathrm{P}$ 值（T 检验） \\
\hline sav & -0.0314 & 0.0027 & -0.0314 & 0.0030 \\
\hline 1en & 0.0135 & 0.0003 & 0.0135 & 0.0003 \\
\hline $\operatorname{siz}$ & -0.0755 & 0.0339 & -0.0755 & 0.0366 \\
\hline bk_2 & & & -0.0273 & 0.0215 \\
\hline bk_3 & & & -0.0198 & 0.0540 \\
\hline bk_4 & & & -0.0361 & 0.0462 \\
\hline $\mathrm{d} 1$ & 0.0010 & 0.5495 & 0.0010 & 0.5605 \\
\hline $\mathrm{d} 2$ & -0.0010 & 0.1041 & -0.0010 & 0.1108 \\
\hline cons & 0.0454 & 0.0098 & 0.0646 & 0.0163 \\
\hline
\end{tabular}

在 LSDV 估计中, bk_1 为大型银行的个体虚拟变量, bk_2 为中小型银行的个体虚拟变量, bk_3 为农村 合作机构的个体虚拟变量, bk_4 为村镇银行的个体虚拟变量。为了避免虚拟变量陷阱问题, bk_1 被省略, 其个体差异值定为 0 , 剩余三个变量的个体差异值为相对于 bk $1 （=0)$ 的调整值, 这反映了四类银行的净 
利差的差异。

接下来对模型的估计结果进行解释与分析:

1、存款占总资产的比重 sav 的系数显著为负，贷款占总资产的比重 $1 \mathrm{en}$ 的系数显著为正，这与实际 中存贷款余额对净利差影响的方向是一致的。但存款比重系数的绝对值要远大于贷款比重系数的绝对值, 这就说明了存款对银行净利差的影响要大于贷款带来的影响, 进一步证实了利率市场化改革中 “先贷款, 后存款” 原则的正确性。

2、行业地位指标 siz 的系数显著为负, 表示伴随着某类银行总资产占全行业总资产比重的增大, 该类银 行的净利差是逐渐降低的。这个指标的估计值出现了反直觉的特点, 而且这一结果与大部分的研究并不一 致。

3、对代表四类银行净利差的个体差异项（bk_1-bk_4）进行由大到小的排序。从结果可以看出， 大型银行的规模最大, 净利差也最大, 其余三类银行的规模较小, 利差也较小。更特殊的问题在于, 后三 类银行的净利差排序与其规模排序并不一致，根据模型估计值计算，农村合作机构的净利差大约比中小型 银行的净利差高出 75 个基点。从这一点可以看出, 农村合作机构通过发挥自身在农村和乡镇的优势, 可 以获得较好的盈利水平。

从上述的分析中可以总结出，并非规模越大的金融企业的盈利能力越强，在规模扩张的同时，能否发 挥自身的优势提高综合服务水平，处理好规模和盈利水平的关系，使得自身的净利差不至于被压缩到较小 的状态，是决定金融机构能否承受基准利差缩小所带来的政策冲击的重要因素。

4、对于政策虚拟变量 $\mathrm{d} 1$ 和 $\mathrm{d} 2$ 的系数估计值, 在 $95 \%$ 的显著性水平上无法通过检验, 意味着在这个显 著性程度上政策的效果并不明显。但仍需注意的一点是固定效应和 LSDV 对 $\mathrm{d} 2$ 系数的估计结果的显著性接 近 $90 \%$ 的水平, 虽然估计的系数为 -0.001 （即 10 个基点的负面影响），但是这个负面影响应该被认为是真 实存在的。

接下来针对政策效果并不十分显著以及表现出一定程度的负效应两个方面进行分析。

\section{2 利率市场化改革政策的效果分析}

针对政策虚拟变量的估计结果并不十分显著这一问题，需要综合宏观经济因素和政策的持续性两方面 加以解释。当然, 银行在这一过程中的主动性调整也是无法忽视的重要原因。

在此，本文利用季度 GDP 同比增长率 ${ }^{4}$ 来考察宏观经济水平，利用月度 CPI 同比变化率来表示通货膨 胀水平, 利用一年期 SHIBOR 月度均值代表货币市场利率水平。研究发现, 从我国利率市场化改革措施实 施的历史来看, 缩减基准利差的措施通常选择在通胀率低的时期进行, 而本文所考察的这两次改革措施, 也正是 CPI 持续下降并稳定在 $2 \%$ 左右的时期, 对比威海的 CPI 情况，同样也处于下降趋势之中。再从政策 的持续性角度来讲，虽然自 2009 年以来，中国人民银行实施的 7 次利率政策中的前 5 次都没有改变基准 利差, 但是却对中长期存贷款利率进行了调整，使得中长期存贷款利差一直处于缩小的状态。这种长期渐 进而又连续不断的改革方式，不仅使得改革给经济带来的被动冲击减少，而且也使得银行逐渐适应了利差 逐渐缩小的政策环境。同时，银行也在努力提高中间业务收入的比重，同时积极开发中小企业客户，使得 盈利的来源更加多样化。这样的政策持续性, 使得银行更有能力来应对政策带来的不良影响。针对政策冲 击的负面作用, 仍然需要结合宏观经济背景来理解。 


\section{4 结论与建议}

综合以上的分析, 我们可以得到以下结论: 第一, 依据威海市四类银行的净利差的类别差异估计系数, 可以对四类银行承受基准利差政策冲击的基础能力水平进行由强到弱的排序: 中资全国性大型银行、农村 合作金融机构、中资全国性中小型银行与村镇银行。四大类银行中，中资全国性中小型银行的规模比重上 升明显, 但净利差处于低位, 其承受政策冲击的能力值得关注。第二, 2012 年中期实施的利率市场化改革 政策, 并没有对威海市银行业的净利差造成明显的影响。第三, 由于两项改革政策几乎同时实施, 仍然对 银行业的净利差造成一定的负面作用。

根据分析结论，我们提出以下政策建议:

第一, 政策实施的时间应尽量选择在低通胀、稳定增长或高速增长的时期。

第二, 对于银行业来讲，中资全国性大型银行应在保持原有的规模优势的基础上，进一步提高自身的 管理水平和服务能力, 提高中间业务的规模和技术水平, 增强自身的金融创新能力, 从而为利率市场化改 革创造更好的微观基础。对于中资全国性中小银行来讲, 在其努力向地方扩展自身业务范围的进程中, 更 要注重增强综合服务水平和议价能力, 发挥自身的竞争优势, 实现规模与盈利能力的均衡增长。对于地方 性的农村合作金融机构, 由于其服务对象主要分布于农村和乡镇, 其主要收入来源仍然会高度依赖净利差, 鉴于美国利率市场化改革过程中, 储蓄机构因存贷款期限结构不合理, 导致利率倒挂而大规模倒闭的教训, 农村合作金融机构尤其要注重管理资产和负债的期限结构和数量结构, 提高利率风险管理水平和资产负债 综合管理水平。对于尚处于初期发展阶段的村镇银行来讲, 一定要抓住当前农村地区存贷款市场竞争尚未 十分激烈的时机, 更加深入农村地区, 更大程度的抢占农村市场, 通过发挥小银行的优势并创造稳定的客 户群, 来增强自身的竞争能力和盈利水平。

\section{参考文献}

[1]萨奇. 利率市场化与高利率关系的国际经验 $[J]$. 国际金融研究, 1996 (1).

[2]钟伟, 沈闻一. 银行业净利差的国际比较及对中国的实证分析 [J]. 管理世界, 2006 (9).

[3] 黄金老.利率市场化与商业银行风险控制[J].经济研究, 2001 (1).

[4]王玨帅. 我国利率市场化进程中商业银行盈利状况经验分析 [J].财经问题研究, 2012 (8).

[5]高超. 我国利率政策与国有商业银行盈利能力的相关性分析 [J]. 产业与科技论坛, 2012 (3).

\section{References}

[1] SA. Relationship between market interest rates and high rates of international experience [J]. international financial research, 1996 (1).

[2] Zhong Wei, Shen Wen. An international comparison of net interest margin in banking and empirical analysis of China [J]. management world, 2006 (9)

[3] Huang Jinlao. Interest rate liberalization and risk control of commercial banks [J]. economic research, 2001 (1)

[4] Wang Jueshuai. The process of China's commercial banks in the interest rate market profitability analysis experience [J]. research on financial and economic issues, 2012 (8).

[5] Gao Chao. Analysis of the relationship between interest rate policy and profitability of state owned commercial banks [J]. Forum on industry and technology, 2012 (3) 